Borneo Journal of Sciences and Technology, Volume (2), Issue (1), Pages: 19-26

DOI: https://doi.org/10.35370/bjost.2020.2.1-05

e-ISSN: 2672-7439

(C) 2018, UCTS Publisher.

Submitted: $7^{\text {th }}$ November $2019 \quad$ Accepted: $5^{\text {th }}$ December $2019 \quad$ Published: $31^{\text {th }}$ January 2020

\title{
Effect of Different Hot Press Temperature on Physical and Mechanical Performance of Microwave Pre-treated Oil Palm Fronds (OPaF) Composite Board With Addition of Urea Formaldehyde Resin
}

\author{
Ellisha Iling and Dayang Siti Hazimmah Ali \\ School of Engineering and Technology, University College of Technology Sarawak, 96000 Sibu, \\ Sarawak, Malaysia
}

\begin{abstract}
This paper focused on the effect of different hot press temperature on the microwave pre-treated oil palm fronds $(\mathrm{OPaF})$ composite board. The oil palm fronds were dried and crushed into smaller particles by using a crusher machine. Sieved oil palm fronds particles that retained on the $0.60 \mathrm{~mm}$ sieve mesh were selected to manufacture composite boards with a targeted density of $0.8 \mathrm{~g} / \mathrm{cm}^{3}$. The $20 \mathrm{~cm} \times 20 \mathrm{~cm} \times 0.50 \mathrm{~cm}$ composite boards were manufactured by applying three different hot press temperatures of $140^{\circ} \mathrm{C}, 160^{\circ} \mathrm{C}$ and $180^{\circ} \mathrm{C}$, respectively. A pressure of $7 \mathrm{MPa}$ of the hot press machine was applied for each composite board's production. The physical and mechanical performance of oil palm fronds composite boards were tested according to the Japanese Industrial Standard (JIS A5908:2003). The physical and mechanical properties of composite board showed improvement in performance as the hot press temperature being elevated. The internal bonding strength obtained were $5.06 \mathrm{~N} / \mathrm{mm}^{2}, 6.23 \mathrm{~N} / \mathrm{mm}^{2}$ and $5.96 \mathrm{~N} / \mathrm{mm}^{2}$, respectively as the hot press temperature is elevated from $140^{\circ} \mathrm{C}$ to $180^{\circ} \mathrm{C}$. The results of modulus of rupture were $16.84 \mathrm{~N} / \mathrm{mm}^{2}, 18.58 \mathrm{~N} / \mathrm{mm}^{2}$ and $20.11 \mathrm{~N} / \mathrm{mm}^{2}$. The cross-section and surface morphologies of fabricated boards were characterized via scanning electron microscopy (SEM). The images of samples with hot press temperature of $180{ }^{\circ} \mathrm{C}$ showed flatten particle structures and more distributed glue lines compared to the other two samples.
\end{abstract}

Keywords: Hot press temperature, microwave pretreated, Elaeis Guineensis fronds, physical and mechanical performance.

\section{INTRODUCTION}

In developing countries which become major producer and exporter of oil palm (Elaeis guineensis), management of oil palm biomass has always become an issue. This is because approximately $90 \%$ of the Elaeis guineensis tree raw materials consist of biomass wastes and only $10 \%$ of oil [1].

Oil palm fronds (OPF) are one of the most known major contributors to the oil palm residue $[2,3]$. OPF is often obtained either during fruit harvesting or palm pruning period throughout the year [4]. After 25 years of cultivation, oil palm trees usually undergo replanting process and a mature palm tree generally produces approximately 41 fronds and contributed to crown yields of around 115 kilograms per palm of dry fronds [5].

Composite is a material formed through the combination of two or more micro- or macroconstituents having a different structure and chemical composition. The significant of the composite material is having the superior properties in comparison to the individual constituents [6].

Microwave pre-treatment is classified as a physical pre-treatment [7]. It is known as the simplest pretreatment method. This process does not require high energy consumption and usage of any solvents or auxiliary chemicals. According to Tajuddin, Ahmad [8], the performance of fabricated boards improved after underwent microwave pre-treatment before being consolidated via hot press machine.

Also, during hot pressing of boards, the elevation of hot press temperature helps in the degradation of a chemical component in natural fibres. Hence, improve the internal binding properties of the composite board [9].

Selection of hot press temperature for the composite preparation depends on the standard melting temperature of resins used. The typical hot press temperature applied for composite board fabricated with urea-formaldehyde (UF) is $150^{\circ} \mathrm{C}$ to $160^{\circ} \mathrm{C}$. Besides, the softening 
temperature of lignin at $12 \%$ moisture content is $115^{\circ} \mathrm{C}$ to $120^{\circ} \mathrm{C}[10]$.

Therefore, the objective of this research was to study the effect of temperature on the properties of microwave pre-treated Elaeis guineensis frond composite boards with $10 \%$ urea-formaldehyde. Three different hot press temperatures of $140^{\circ} \mathrm{C}, 160^{\circ} \mathrm{C}$ and $180^{\circ} \mathrm{C}$, respectively were studied. The physical and mechanical performances of all $\mathrm{OPaF}$ Composite Board were evaluated. Also, the cross-section and surface morphologies of fabricated boards were characterized to determine the bonding quality of the experimental composite boards as a function of applied pressure.

\section{MATERIALS AND METHODS}

Fresh OPF was obtained from Zumida Oil Palm Plantation Sibu. The OPF was chipped by using a saw machine before oven-dried to $6-8 \%$ moisture contents with a heating temperature of $100^{\circ} \mathrm{C}$. The oven-dried OPF chips were then further reduced into smaller particles by using a crusher machine.

The OPF particles that retained on the $0.60 \mathrm{~mm}$ sieve mesh were selected to be used in the manufacturing of composite board fabrication. The OPF particles were microwave pre-treated for one minute at 700 watts. An addition of $10 \%$ low formaldehyde emission ureaformaldehyde (UF) resins mixed with $1 \%$ of hardener (ammonium chloride) was used in the composite board making. The composite boards were made on a laboratory scale by standard techniques and controlled conditions. The OPF particles were weighed and placed into a steel mould with dimension of $(20 \times 20 \times 0.50)$ $\pm 0.02 \mathrm{~cm}$ with targeted densities of $0.8 \mathrm{~g} / \mathrm{cm}^{3}$. The mats were compressed by using hot press machine under the pressure of $7 \mathrm{MPa}$ with platen temperature of $140{ }^{\circ} \mathrm{C}, 160$ ${ }^{\circ} \mathrm{C}$, and $180^{\circ} \mathrm{C}$, respectively for 20 minutes.

The pressed composite boards were then left cooled followed by cutting of test specimens based on Japanese Industrial Standards (JIS A5908:2003) [11]. The test specimens were then conditioned in a conditioning chamber at a temperature of $20 \pm 2{ }^{\circ} \mathrm{C}$ and relative humidity of $65 \pm 5 \%$ for seven days.

\section{Physical Testing}

The physical properties of OPaF Composite Board were tested by performing water absorption (WA) and thickness swelling (TS) tests. For each OPaF Composite Board group, specimens with a dimension of $5 \mathrm{~cm} \times 5$ $\mathrm{cm}$ were prepared. All specimens were soaked in distilled water for 24 hours before measurement of thickness swelling were taken. Each sample was then weighed to determine the water absorption values.

\section{Mechanical Testing}

Internal bonding (IB) test and modulus of rupture (MOR) were performed to evaluate the mechanical properties of OPaF Composite Board. The Hegewald and Peschke Testing Machine with a load capacity of $10 \mathrm{kN}$ was employed. The testing speeds applied for IB test and MOR test were $2 \mathrm{~mm} / \mathrm{min}$ and $10 \mathrm{~mm} / \mathrm{min}$, respectively.

\section{Morphological Characterization}

A scanning electron microscopy (SEM) model JEOL JCM-6000 was used to analyse the effect of different level of hot pressing temperature on the internal and surface textures of $\mathrm{OPaF}$ Composite Board. Each specimen with dimensions of $0.5 \mathrm{~cm} \times 0.5 \mathrm{~cm}$ was prepared from the failure section of IB test specimens. The specimens were gold-coated by an ion sputter coater (JEOL JEC-3000FC Auto Fine Coater) before micrographs of the specimens are taken under high resolution.

\section{RESULTS AND DISCUSSION}

\section{Physical Properties}

Figure 1 shows the thickness swelling (TS) results of $\mathrm{OPaF}$ Composite Board fabricated under hot press temperatures of $140^{\circ} \mathrm{C}, 160^{\circ} \mathrm{C}$ and $180^{\circ} \mathrm{C}$, respectively. The TS of samples shown decreasing in value as the hot press temperature increased from $140^{\circ} \mathrm{C}$ to $180^{\circ} \mathrm{C}$. At the hot press temperature of $140^{\circ} \mathrm{C}$, the TS value measured is $52.10 \%$. As the hot press temperature increased up to $160^{\circ} \mathrm{C}$ and $180^{\circ} \mathrm{C}$, the TS value measured is $29.02 \%$ and $18.48 \%$, respectively. The high TS value measured from $\mathrm{OPaF}$ Composite Board is due to the spongy nature of OPF.

The reduction in TS value of OPaF Composite Board as hot press temperature being increased from $140^{\circ} \mathrm{C}$ to $180^{\circ} \mathrm{C}$ indicated that as hot pressing temperature increased, the degradation of chemicals in OPF particles helped to enhance the activity of particles for easy bonding between particles. Furthermore, high temperature may also help in better gluing of adhesive and subsequently helped in better distribution between the particles, thus it can be thoroughly solidified.

However, continues to rise up of temperature to $185^{\circ} \mathrm{C}$ can results in poor TS condition due to further degradation of UF resins [12] which weaken the structure of $\mathrm{OPaF}$ Composite Board while being immersed in water. 
In addition, the degradation of UF resins can increase the hygroscopicity of $\mathrm{OPaF}$ Composite Board.
Subsequently, allow specimens to swell more and increase the thickness swelling values.

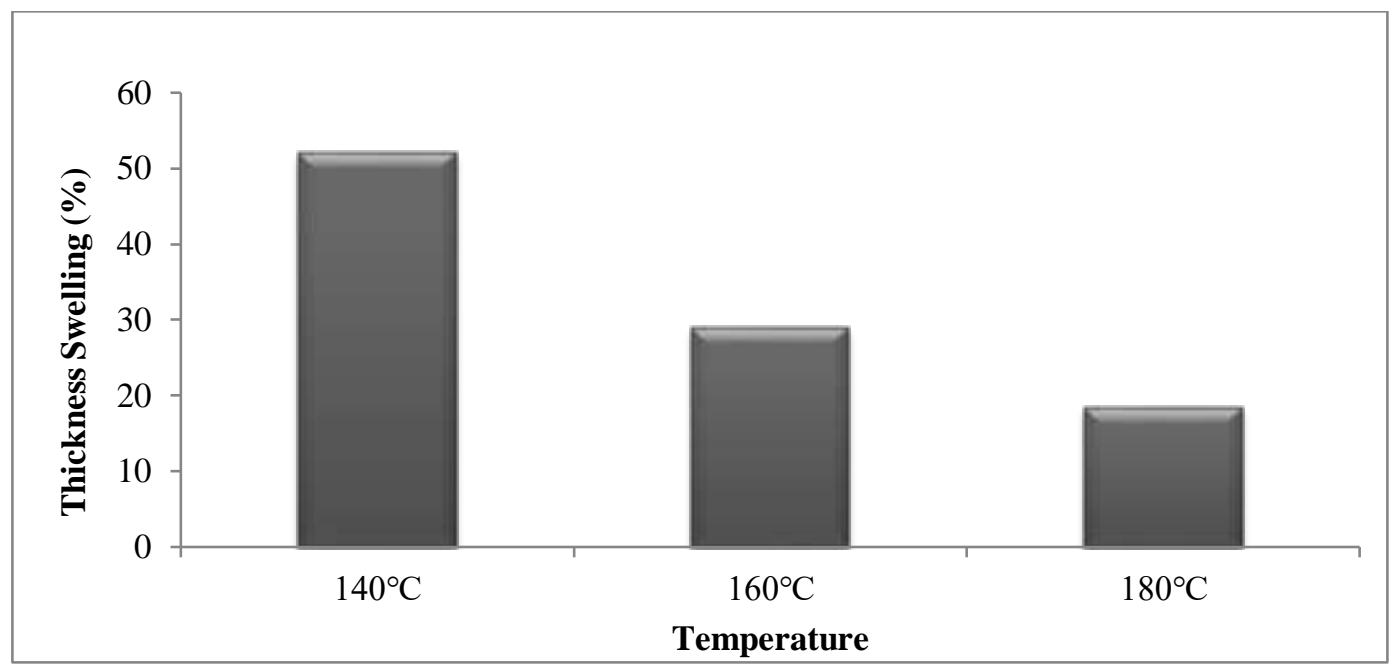

Figure 1: Thickness Swelling of OPaF Composite Board after Immersion of 24 hours

The water absorption (WA) results of OPaF Composite Board when the hot press temperatures were elevated from $140^{\circ} \mathrm{C}$ to $180^{\circ} \mathrm{C}$ is shown in Figure 2. The WA values obtained from each hot press temperature were $134.32 \%, 135.92 \%$ and $122.54 \%$, respectively. From the results obtained, it showed that the difference in WA percentage of $\mathrm{OPaF}$ Composite Board manufactured under hot press temperature of $140^{\circ} \mathrm{C}$ and $180^{\circ} \mathrm{C}$ is $11.78 \%$.

From the bar graphs presented, the WA value is the highest at the hot press temperature of $160^{\circ} \mathrm{C}$ and the lowest at $180^{\circ} \mathrm{C}$. The increased of WA value when hot press temperature is elevated from $140^{\circ} \mathrm{C}$ to $160^{\circ} \mathrm{C}$ is due to uneven compactness of OPaF Composite Board and the presence of voids in between particles that allow more water uptake during immersion [13].

Besides, the hydrophilic nature of UF resins further enhanced the efficiency of water uptake in $\mathrm{OPaF}$ Composite Board [14]. Hence, the WA values obtained were relatively high.

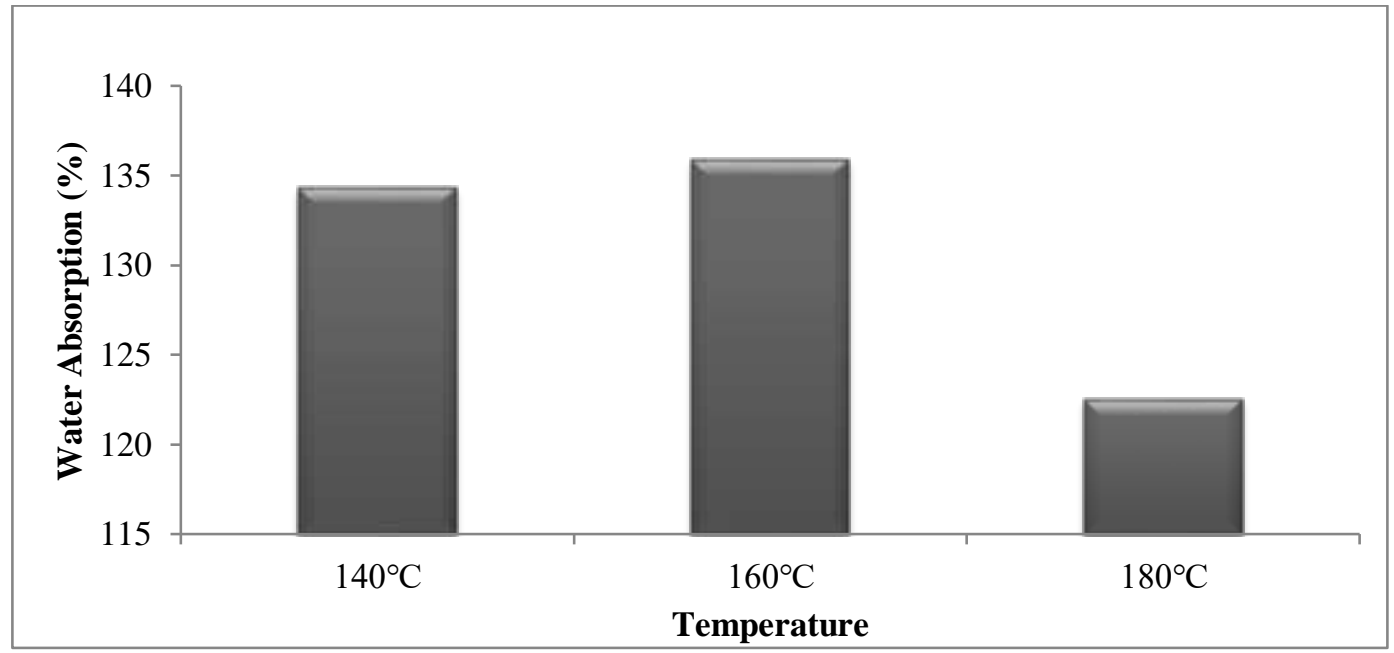

Figure 2: Water Absorption Values of OPaF Composite Board after Immersion of 24 hours 


\section{Mechanical Properties}

Figure 3 shows the internal bonding (IB) strength of $\mathrm{OPaF}$ Composite Board fabricated under hot press temperatures of $140^{\circ} \mathrm{C}, 160^{\circ} \mathrm{C}$ and $180^{\circ} \mathrm{C}$, respectively. IB strength test was conducted to examine the interfacial bonding strength between $\mathrm{OPF}$ particles in $\mathrm{OPaF}$ Composite Board [15].

As the temperature is elevated from $140^{\circ} \mathrm{C}$ to $180^{\circ} \mathrm{C}$, the IB strength values measured are $5.06 \mathrm{~N} / \mathrm{mm}^{2}, 6.23$ $\mathrm{N} / \mathrm{mm}^{2}$ and $5.96 \mathrm{~N} / \mathrm{mm}^{2}$, respectively.

The board fabricated under hot press temperature of $160^{\circ} \mathrm{C}$ has the highest IB strength compared to the rest of $\mathrm{OPaF}$ Composite Board fabrication.
Since the normal hot pressing temperature applied on $\mathrm{UF}$ resins is between $150^{\circ} \mathrm{C}$ and $160^{\circ} \mathrm{C}$ [10], the results obtained through this research showed that the optimum hot press temperature is at $160^{\circ} \mathrm{C}$.

From the trend of bar graphs, it can be concluded that at a hot press temperature of $140^{\circ} \mathrm{C}$ the UF resin is experiencing pre-curing stage [16]. Whereas, at $180^{\circ} \mathrm{C}$, over curing of adhesive took place. Hence, the precuring and over curing of adhesive conditions subsequently contributed to low IB strength in the $\mathrm{OPaF}$ Composite Board.

The overall IB strength results obtained had achieved the requirement of Japanese Industrial Standard JIS A5908:2003.

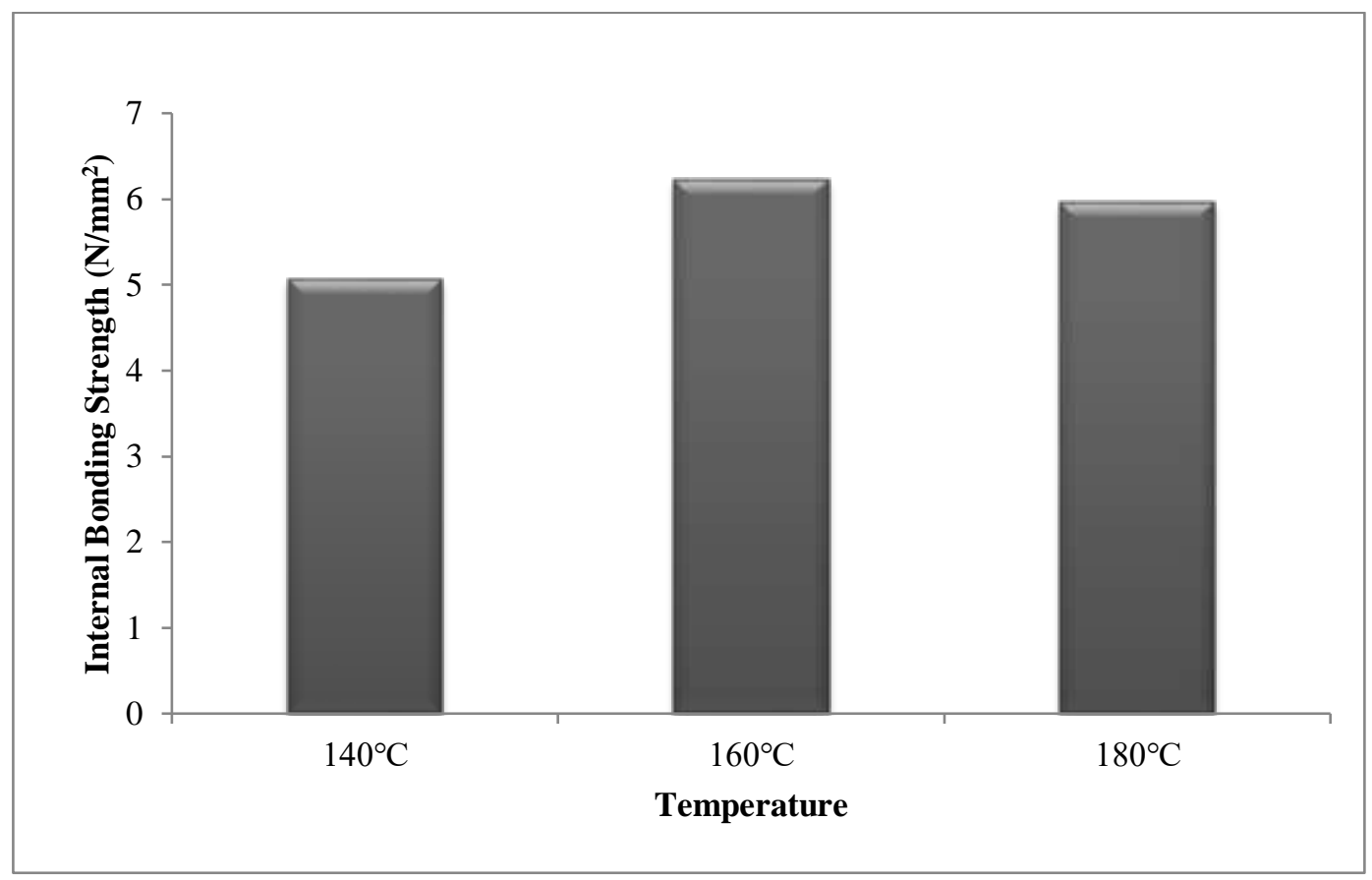

Figure 3: Internal Bonding Strength of OPaF Composite Board

Figure 4 shows that the modulus of rupture (MOR) of OPaF Composite Board improved with increasing hot press temperature. The MOR test was conducted to study the ability of the test piece to resist the maximum bending force perpendicular to its longitudinal axis [17].

At hot press temperature of $140^{\circ} \mathrm{C}$, the MOR value measured is $16.84 \mathrm{~N} / \mathrm{mm}^{2}$. When the temperature increases to $160^{\circ} \mathrm{C}$, the MOR of board increased by
9.36\%. Lastly, when the temperature is increased to $180^{\circ} \mathrm{C}$, the MOR of the board obtained is $20.11 \mathrm{~N} / \mathrm{mm}^{2}$.

It is shown that all MOR results obtained through the present study exceed the minimum requirement of 8.0 $\mathrm{N} / \mathrm{mm}^{2}$ stated in JIS A5908:2003 for based particleboard and decorative particleboard classifications. 


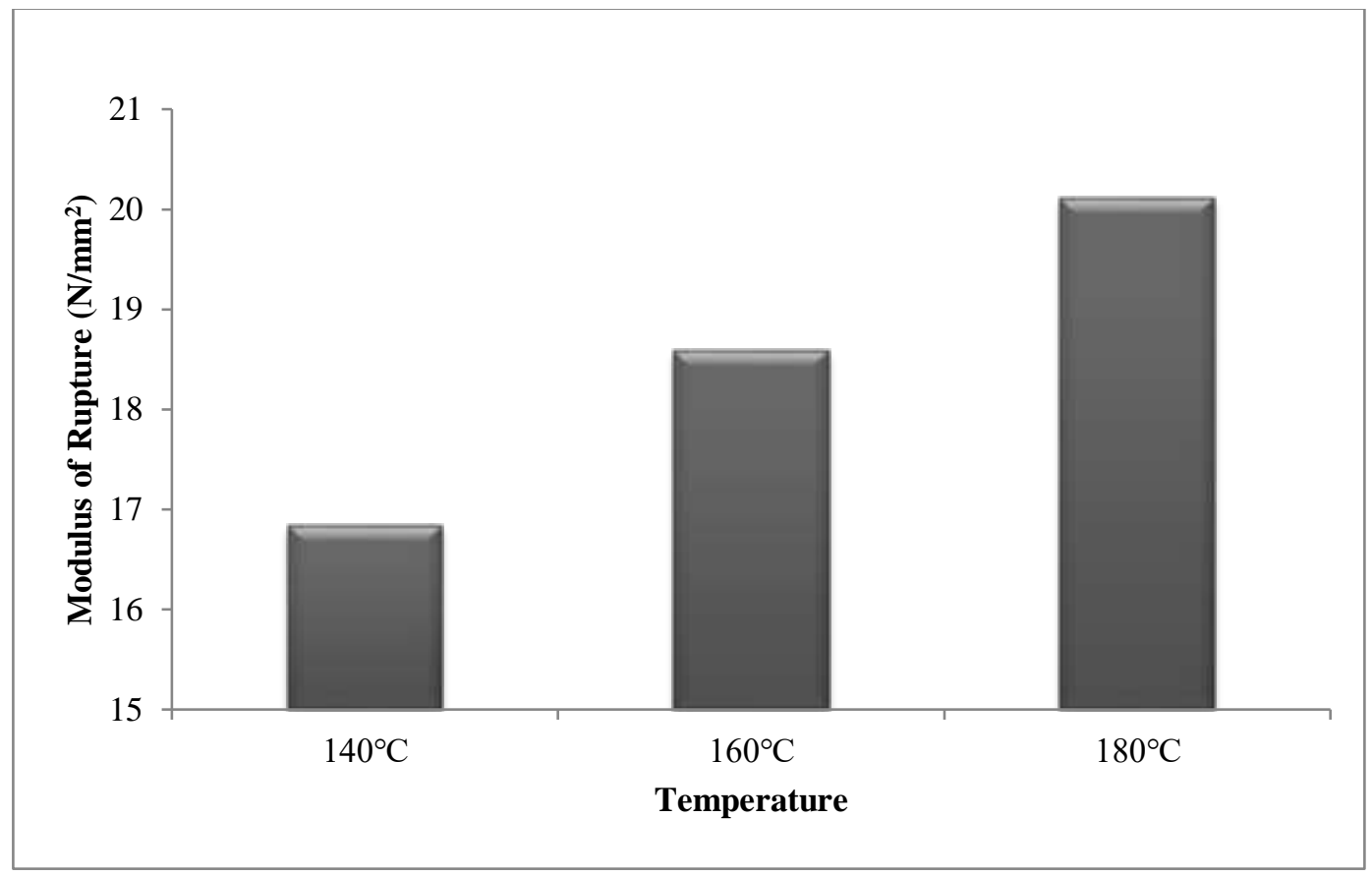

Figure 4: Modulus of Rupture of OPaF Composite Board

\section{Morphological Characterization}

The change in OPaF Composite Board morphologies due to different hot press temperature for OPaF Composite Board is presented in Figure 5, Figure 6 and Figure 7, respectively.

By comparing all micrographs of OPaF Composite Board fabricated under different hot press temperature, the DNA strand-like cellulose internal structure is clearly seen in Figure 6. The obvious deoxyribonucleic acid (DNA) strand-like cellulose internal structure is due to the degradation of lignin and hemicellulose in OPF particles [18].

On the other hand, irregular aggregate-like $\mathrm{OPaF}$ Composite Board cross-section micrograph can be seen in Figure 5(a) and a little glue line on OPaF Composite Board surface in Figure 5(b). The undisturbed structure observed in $\mathrm{OPaF}$ Composite Board cross-section shows that at a hot press temperature of $140^{\circ} \mathrm{C}$, lignocellulose components are experiencing minimal degradation. Whereas, a little glue line seen indicates that only a little amount of urea-formaldehyde (UF) resin started to melt and cure at $140^{\circ} \mathrm{C}$.

Micrographs in Figure 7 obviously showed flatten particle structures and distributed glue lines that covered the OPaF Composite Board cross-section and surface respectively. At a hot press temperature of $180^{\circ} \mathrm{C}$, most chemical components in $\mathrm{OPaF}$ Composite Board were melted and degraded whereas some of the UF resin may have been over cured by which subsequently lower the mechanical properties of $\mathrm{OPaF}$ Composite Board.

Since the standard range of hot press temperature to fabricate a board with UF resin is $150^{\circ} \mathrm{C}$ to $160^{\circ} \mathrm{C}$ [10], the little glue line shown in Figure 5 explained that the pre-curing of UF had taken place when the $\mathrm{OPaF}$ Composite Board was pressed under a temperature of $140^{\circ} \mathrm{C}$.

As the temperature increased to $160^{\circ} \mathrm{C}$, the UF resin was expected to experience perfect curing condition. Besides, the fabrication of boards at $160^{\circ} \mathrm{C}$ pressing temperature allows continuous melting of lignocellulose structure in OPF particles to act as a natural binder. When the hot press temperature applied is beyond the standard temperature range required by UF resin for fabrication, failure in achieving good mechanical and physical properties of the composite will occur. 
Effect of Different Hot Press Temperature on Physical and Mechanical Performance of Microwave Pre-treated Oil Palm Fronds $(\mathrm{OPaF})$ Composite Board With Addition of Urea Formaldehyde Resin

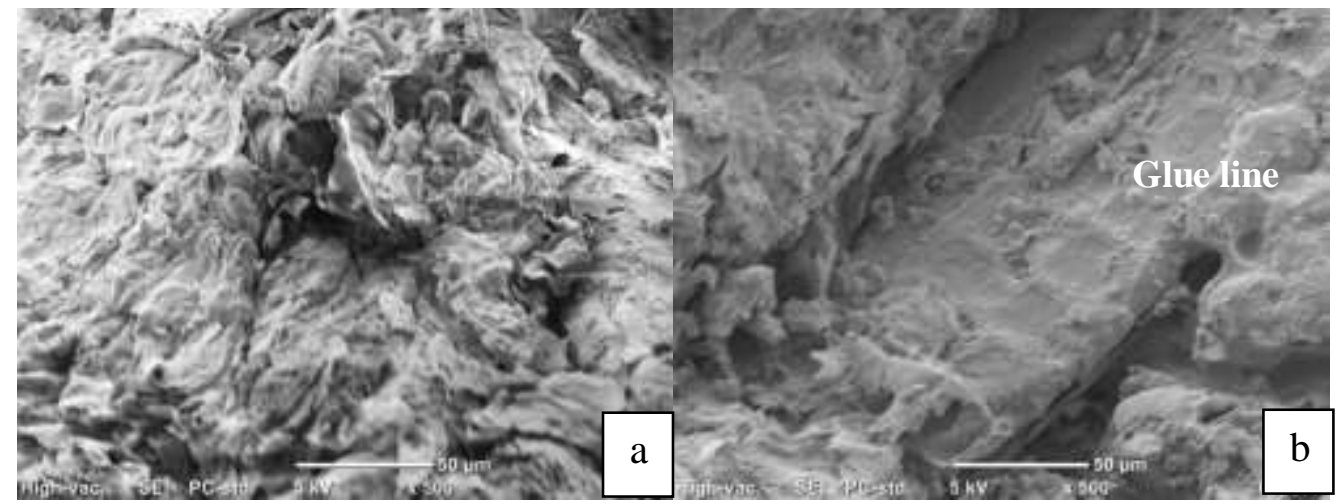

Figure 5: Cross Section (a) and Surface (b) Morphologies of OPaF Composite Board Fabricated under Hot Press Temperature of $140^{\circ} \mathrm{C}$ at $\times 500$ Magnification.

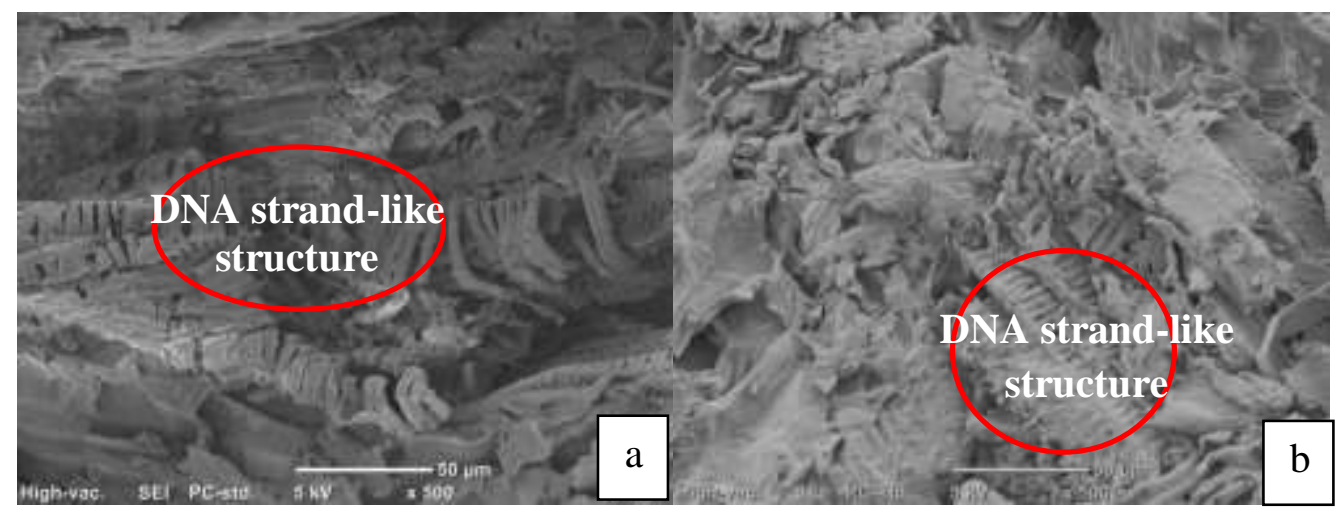

Figure 6.1: Cross Section (a) and Surface (b) Morphologies of OPaF Composite Board Fabricated under Hot Press Temperature of $160^{\circ} \mathrm{C}$ at $\times 500$ Magnification.

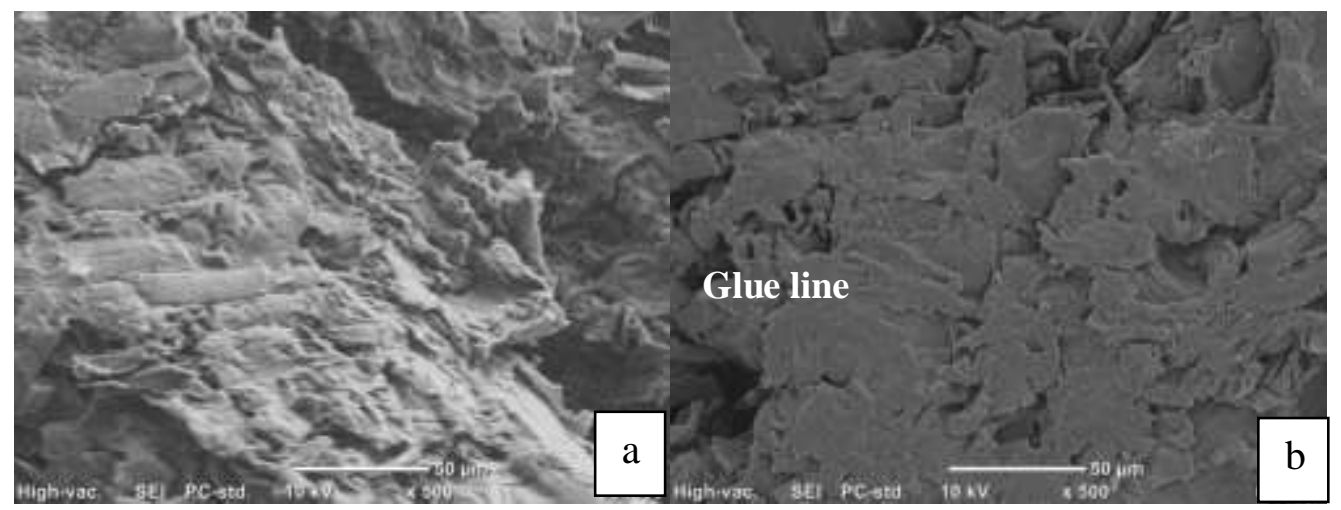

Figure 7: Cross Section (a) and Surface (b) Morphologies of OPaF Composite Board Fabricated under Hot Press Temperature of $180^{\circ} \mathrm{C}$ at $\times 500$ Magnification. 


\section{CONCLUSION}

The physical and mechanical properties of $\mathrm{OPaF}$ Composite Board met the particleboard specifications as mentioned in JIS A5908:2003. The hot press temperature applied influenced the overall performance of the OPaF Composite Board. Temperature increases improved the TS, WA and MOR of the boards. The IB showed the highest values when the board produced at $160^{\circ} \mathrm{C}$ hot press temperature.

\section{ACKNOWLEDGEMENT}

The authors thank the University College of Technology Sarawak (UCTS) for the financial support and allowing the studies to be conducted at their research facilities. The authors would also like to acknowledge Zumida Oil Palm Plantation Sibu for providing the fronds and Hexzachem Sarawak Sdn. Bhd for providing the low formaldehyde emission urea-formaldehyde resins.

\section{REFERENCES}

[1] Abdullah, N. and F. Sulaiman, The oil palm wastes in Malaysia, in Biomass Now Sustainable Growth and Use, M.D. Matovic, Editor 2013, INTECH. p. 75-98.

[2] Ooi, Z. X., Teoh, Y. P., Kunasundari, B., \& Shuit, S. H. (2017). Oil palm frond as a sustainable and promising biomass source in Malaysia : A review. Environmental Progress \& Sustainable Energy 36(6), 1864-1874. doi: doi:10.1002/ep. 12642

[3] Guangul, F. M., Sulaiman, S. A., \& Raghavan, V. R. (2012). Elemental and thermo-chemical analysis of oil palm fronds for biomass energy conversion. Paper presented at the The 4th International Meeting of Advances in Thermofluids (IMAT 2011), Melaka, Malaysia.

[4] Aljuboori, A. H. R. (2013). Oil palm biomass residue in Malaysia: Availability and sustainability. International Journal of Biomass and Renewables, 13-18.

[5] Sulaiman, O., Salim, N., Nordin, N. A., Hashim, R., Ibrahim, M., \& Sato, M. (2012). The potential of oil palm trunk biomass as an alternative source for compressed wood. BioResources, 7(2), 26882706.
[6] Smith, W. F., \& Hashemi, J. (2011). Foundations of materials science and engineering (5th ed.). New York: McGraw-Hill.

[7] Aguilar-Reynosa, A., Romani, A., RodríguezJasso, R. M., Aguilar, C. N., Garrote, G., \& Ruiz, H. A. (2017). Microwave heating processing as alternative of pretreatment in second-generation biorefinery : An overview. Energy Conver

[8] Tajuddin, M., Ahmad, Z., \& Ismail, H. (2016). A review of natural fibers and processing operations for the production of binderless boards. BioResources, 11(2), 5600-5617.

[9] Hashim, R., Said, N., Lamaming, J., Baskaran, M., Sulaiman, O., Sato, M., . . Sugimoto, T. (2011). Influence of press temperature on the properties of binderless particleboard made from oil palm trunk. Materials and Design, 32, 2520-2525.

[10] Suzuki, S., Shintani, H., Park, S.-Y., Saito, K., Laemsak, N., \& Okuma, M. (1998). Preparation of binderless boards from steam exploded pulps of oil palm (Elaeis guneensis Jacq.) fronds and structural characterization of lignin and wall polysaccharides in steam exploded pulps to be discussed for selfbindings. Holzforschung, 52(4), 417-426.

[11] Japanese Industrial Standards Committee, JIS. (2003). JIS A 5908-2003 particleboards. Tokyo: JIS

[12] Iswanto, A. H., Azhar, I., Supriyanto, \& Susilowati, A. (2014). Effect of resin type, pressing temperature and time on particleboard.

[13] Chiang, T. C., Hamdan, S., \& Osman, M. S. (2016). Effects of density of sago/urea formaldehyde particleboard towards its thermal stability, mechanical and physical properties. Jurnal Teknologi (Sciences \& Engineering), 78(10), 187-197.

[14] Nagieb, Z. A., Nassar, M. A., \& El-Meligy, M. G. (2011). Effect of addition of boric acid and borax on fire-retardant and mechanical properties of urea formaldehyde saw dust composites. International Journal of Carbohydrate Chemistry, 2011, 1-6.

[15] Saad, M. J., \& Kamal, I. (2012). Mechanical and physical properties of low density kenaf core particleboards bonded with different resins. Journal of Science and Technology, 4(1), 17-32.

[16] Xing, C., Riedl, B., Cloutier, A., \& He, G. (2004). The effect of urea-formaldehyde resin pre-cure on the internal bond of medium density fiberboard. Holz Als Roh-Und Werkstoff, 62(6), 439-444.

[17] Green, D. W., Winandy, J. E., \& Kretschmann, D. E. (2010). Mechanical properties of wood Wood handbook - Wood as an engineering material (Centennial ed., Vol. FPL-GTR-190, pp. 5-1 - 545). Madison, Wisconsin: U. S. Department of 
Effect of Different Hot Press Temperature on Physical and Mechanical Performance of Microwave Pre-treated Oil Palm Fronds $(\mathrm{OPaF})$ Composite Board With Addition of Urea Formaldehyde Resin

Agriculture, Forest Service, Forest Products Laboratory.

[18] Lai, L.-W., \& Idris, A. (2013). Disruption of Oil Palm Trunks and Fronds by Microwave-Alkali Pretreatment. BioResources, 8(2), 2792-2804. 